\title{
Vitamin E intake, serum tocopherols and blood pressure in $\mathrm{UK}$ adolescents
}

\author{
Ziyi $\mathrm{Li}^{1}$, Charlotte Evans ${ }^{1}$ and Janet Cade ${ }^{1}$ \\ ${ }^{1}$ Nutritional Epidemiology Group, School of Food Science and Nutrition, University of Leeds, LS2 9JT, Leeds
}

Previous studies suggest that high serum antioxidant levels such as vitamin E could reduce the risk of hypertension ${ }^{(1-3)}$. More evidence is needed to confirm the effects of dietary vitamin E on reducing blood pressure (BP), especially among adolescents. The aim of this study is to determine the relationship between dietary vitamin E intake, serum tocopherols and blood pressure in 10-19 year old UK adolescents.

585 adolescents aged 10-19 years old from the UK National Diet and Nutrition Survey (2008-2012) ${ }^{(4)}$ were included in the analysis. Information was collected by interview, anthropometric data and BP were measured, and dietary data was assessed from a four-day food record. BP data was transformed to systolic BP Z-scores (SBPZ) and diastolic BP Z-scores (DBPZ). Hypertensive adolescents were defined according to the European Hypertension Society Standard ${ }^{(5)}$. Univariable and multivariable linear and logistic regression was undertaken for continuous outcomes (BP values and BPZ-scores) and binary outcomes (hypertension v.s. normal BP) respectively. Confounders were selected according to a Directed Acyclic Graph and likelihood ratio tests.

Mean SBP was $112.0 \pm 10.7 \mathrm{mmHg}$ and mean DBP was $63.1 \pm 8.5 \mathrm{mmHg} .7 .2 \%$ of the total sample was hypertensive. Dietary intake of vitamin $\mathrm{E}$ was $8.8 \pm 4.2 \mathrm{mg} / \mathrm{day}$. No significant relationship between dietary vitamin $\mathrm{E}$ and serum tocopherols was found. In the fully adjusted linear regression, each $1 \mathrm{mg}$ increase in daily vitamin $\mathrm{E}$ intake was associated with $0.03(95 \% \mathrm{CI}$ : -0.07 to 0.00$)$ decrease in DBPZ $(\mathrm{p}=0.048)$, and every $1 \mu \mathrm{mol} / \mathrm{L}$ increase in serum $\alpha$-tocopherol was associated with $0.005(95 \%$ CI: -0.01 to -0.0001$)$ decrease in DBPZ $(p=0.047)$. But no relationship was found with SBPZ or BP values. In the adjusted logistic regression, higher dietary vitamin $\mathrm{E}$ intake was found to reduce the risk of hypertension $(\mathrm{OR}=0.789,95 \% \mathrm{IC}: 0.64$ to 0.96 , $\mathrm{p}=$ 0.019). Associations between dietary vitamin E intake/serum $\alpha$-tocopherol and SBPZ/DBPZ could be found in the following table.

\begin{tabular}{|c|c|c|c|c|}
\hline Nutrients & $\beta$-coefficient & \multicolumn{2}{|c|}{$95 \% \mathrm{CI}$} & $\mathrm{p}$ Value \\
\hline \multicolumn{5}{|c|}{ With systolic blood pressure Z-scores } \\
\hline Dietary vitamin E intake (mg) & $-0 \cdot 026$ & $-0 \cdot 058$ & $0 \cdot 006$ & $0 \cdot 110$ \\
\hline Serum $\alpha$-tocopherol $(\mu \mathrm{mol} / \mathrm{L})$ & -0.004 & $-0 \cdot 010$ & $0 \cdot 001$ & $0 \cdot 148$ \\
\hline \multicolumn{5}{|c|}{ With diastolic blood pressure $Z$-scores } \\
\hline Dietary vitamin E intake (mg) & -0.034 & -0.067 & -0.0003 & $0 \cdot 048^{*}$ \\
\hline Serum $\alpha$-tocopherol $(\mu \mathrm{mol} / \mathrm{L})$ & -0.005 & $-0 \cdot 010$ & -0.0001 & $0 \cdot 047^{*}$ \\
\hline
\end{tabular}

$* \mathrm{p}<0.05$

In conclusion, higher dietary vitamin $\mathrm{E}$ intake and serum $\alpha$-tocopherol were found to have an association with reduced DBPZ and reduced risk of hypertension in UK adolescents aged 10-19 years.

1. Rodrigo R, Prat H, Passalacqua W et al. (2008) Clin Sci (Lond) May;114(10):625-634

2. Jiang Q. (2014) Free Radic Biol Med Jul;72:76-90.

3. Rumbold A.R., F.H. Maats et al. (2005) Eur J Obstet Gynecol Reprod Biol 119(1):67-71.

4. Public Health England. (2014) National Diet and Nutrition Survey: Results from Years 1-4 (combined) of the Rolling Programme (2008/20092011/12): Executive summary.

5. NHBPEP-working-group. (2004) Pediatrics Aug;114(2 Suppl 4th Report):555-576. 